\section{British Steel Castings Research Association}

THE British Steel Castings Research Association has entered into an arrangement with the Steel Founders' Society of America for the exchange of information at their respective annual conferences. Each Association will, in alternate years, invite the other to nominate a speaker to address its annual conference on a selected subject. The scheme is being initiated this year with an invitation to representatives of the British Steel Castings Research Association to address the Steel Founders Society of America Technical and Operating Conference, to be held in Cleveland, Ohio, during November 11-13, on the subject of the applieation of the graphite-rod resistor furnace to steel foundry practice, and the use in steel foundries of the immersion pyrometer for the measurement of liquid steel temperatures. This paper will be presented by Mr. T. A. Cosh, head of the British Steel Castings Research Association's steelmaking section, and Mr. L. W. Saunders, chief metallurgist, Lake and Elliot, Ltd.

\section{British Iron and Steel Institute Translation Service}

Ar the suggestion of the British Iron and Steel Research Association, the Iron and Steel Institute has agreed to organize a co-operative translation service. Plans are already well advanced, and a number of companies in the industry are collaborating with the Institute in setting up the service. The scheme will benefit the industry in two ways : not only will the range of available translations of foreign technical papers, including Russian publications, be considerably widened, but also much unnecessary duplication of effort will be avoided. Translations prepared by individual companies will be passed to the central 'pool', and these will be supplemented by translations from other sources. An index is currently being compiled of those translations made since 1950 which are still available, and lists of newly produced material and of translations in course of preparation will be published at regular intervals by the British Iron and Steel Research Association, the British Tron and Steel Federation and the Institute itself. Although primarily devised to serve the needs of the iron and steel industry, the new service will nevertheless be available to all who wish to take advantage of the facilities offered. An agreed scale of charges has been laid down which includes provision for substantial reductions where a number of copies of any individual paper are required. Inquiries should be addressed to the British Iron and Steel Research Association, 11 Park Lane, London, W.1.

\section{International Group for the Study of the Fauna of} the Soil

DurING the Sixth International Congress of Soil Science held in Paris in 1956, zoologists specializing in the study of the fauna of the soil formed an inter. national group with the object of providing a means for the exchange of information among workers in this field. To achieve this aim, a News Bulletin is being published, and in addition intemational colloquia on particular aspects of the subject will be held at intervals. The first number of the Bulletin, which appeared in May, includes a questionnaire requesting details of current research projects together with information of animal groups studied. The results of this inquiry will be published in future numbers of the Bulletin, copies of which can be obtained from J. d'Aguilar, Station centrale de Zoologie agricole, Route de St.-Cyr, Versailles. The first colloquium, devoted to "Methods of Research in Soil Zoology", will be held at Rothamsted Experimental Station, Harpenden, Hertfordshire, during July 10-14, 1958, immediately prior to the International Zoological Congress to be held in London during July 16-23. The next issue of the News Bulletin will give the programme and other details of the colloquium.

\section{Sugar Research in Mauritius}

THE annual report for 1956 of the Mauritius Sugar Industry Research Institute (pp. $92+x x$. Réduit, 1957) includes papers on cane breeding, nutrition, soils, diseases and pests, weed control, cultivation and irrigation, effects of rainfall on production, and sugar manufacture. Both the total sugar pro. duction and the yield per unit area established new records. Only a few points from the research reports can be noted here. Breeding and selection studies have been continued along the usual lines for the erop. The induction of arrowing, that is, flowering, by photoperiodic treatments is to be attempted. Some interesting information has been obtained from mineral analyses of the juice of six cane varieties grown under different conditions of fertility and climate. For potassium, magnesium and calcium a strong varietal effect was found; for phosphate, however, the varietal effect appears to be weak with the varieties tested. The generally lower status of juices from high rainfall areas in all minerals has been noted. From the results obtained it would appear that the effect of increasing nitrogenous fertilization on the potassium and phosphate contents of juice is governed by whether or not an increase in yield occurs. With an increase in yield both potassium and phosphate decrease, but when no increase in yield is obtained the potassium and phosphate levels of the juice remain approximately constant irrespective of the amount of nitrogen applied to the crop. Foliar diagnosis has been used to advantage in determining the nutritional requirements of sugar cane in different areas. Indeed, the year 1956 marks the end of the first decade of organized control of fertilizer treatment, chiefly phosphate and potassium, based on this technique.

\section{Auxin Inhibition in Lunularia}

IN the course of earlier investigations of the gemmæ of Marchantia and Lunularia, the possible existence of the phenomenon of apical dominance, as exemplified by the higher plants, was noted by C. D. LaRue and S. Narayanaswami. It is well known that the gemmæ of liverworts do not germinate within the gemma cup unless they are detached from the thallus, nor are adventitious buds formed on healthy thalli. These and related observations suggested a programme of investigations from which some interesting results have accrued (New Phytol., 56, 61 ; 1957). Using Lunularia, it was found that excision of the upper halves of thalli above the gemma cups caused the gemmæ within the cups to germinate. Mutilations such as puncturing, slitting, excision of wings, etc., did not affect the gemmæ so long as the apical notches and the midrib regions were intact. This indicates the action of auxin inhibitors from the tips of thalli rather than the effect of a wound stimulus. The upper halves of thalli isolated by transverse cuts do not regenerate adventitious buds, whereas the basal halves do so from the cut ends. The regenerated 